\title{
Wear resistance of cast irons used in brake disc rotors
}

\author{
G. Cueva $^{\text {a }}$, A. Sinatora ${ }^{\text {b }}$, W.L. Guesser ${ }^{\text {c }}$, A.P. Tschiptschin ${ }^{\mathrm{a}, *}$ \\ ${ }^{a}$ Metallurgical and Materials Engineering Department, Av. Prof. Mello Moraes 2463, São Paulo, SP, Brazil \\ b Mechanical Engineering Department, University of São Paulo, São Paulo, SP, Brazil \\ c Tupy Foundry Company (Indústria de Fundição Tupy), University of the State of Santa Catarina, Florianopolis, Brazil
}

\begin{abstract}
The wear resistance of three different types of gray cast iron (gray iron grade 250, high-carbon gray iron and titanium alloyed gray iron), used in brake disc rotors, was studied and compared with the results obtained with a compact graphite iron (CGI). The wear tests were carried out in a pin-on-disc wear-testing machine, the pin being manufactured from friction material usually used in light truck brake pads. The rotating discs $(500 \mathrm{rpm})$ were subjected to cyclical pressures of $0.7,2$ and $4 \mathrm{MPa}$ and forced cooled.

The wear was measured by weighing discs and pads before and after the test. The operating temperatures and friction forces were also monitored during each test.

The results showed that compact graphite iron reached higher maximum temperatures and friction forces as well as greater mass losses than the three gray irons at any pressure applied. However, when compact graphite iron was tested with lower applied pressures and same friction forces sustained by the gray iron rotors, CGI presented the same performance, as did the gray cast iron.
\end{abstract}

(C) 2003 Elsevier Science B.V. All rights reserved.

Keywords: Compact graphite iron; Gray iron; Brake disc; Wear

\section{Introduction}

The optimization of automotive vehicles braking systems, subjected to mechanical and thermal stresses, depends on a combination of properties. In general, a complex state of stress is found and it is practically impossible to select a material and design a component based only on one of these properties. The material used in brake rotors should be able to bear thermal fatigue and should absorb and dissipate, as soon as possible, the heat generated during braking [1].

The hydraulic pressure exerted during typical braking procedures, lies between 2 and $4 \mathrm{MPa}$ [2]. Friction makes rotors reach, during very small periods of time, temperatures as high as $800^{\circ} \mathrm{C}\left(1472^{\circ} \mathrm{F}\right)$, resulting in a thermal gradient between the surface and the core of the rotors, which may reach up to $500^{\circ} \mathrm{C}\left(932^{\circ} \mathrm{F}\right)$ [3].

Traditionally, brake rotors are manufactured in gray iron class $250\left(\mathrm{UTS}_{\min }=250 \mathrm{MPa}\right)$, with a predominantly pearlitic matrix (>95\% pearlite). The automotive industry in the United States has been using a sub-class of this iron, with addition of $\mathrm{Ti}(>200 \mathrm{ppm})$, so as to reduce the friction coefficient and to increase wear resistance [4].

\footnotetext{
* Corresponding author. Tel.: +55-11-3091-5656; fax: +55-11-3091-5243.

E-mail address: antschip@usp.br (A.P. Tschiptschin).
}

Recently, manufacturers have introduced high-carbon, high-conductivity gray iron brake rotors, sometimes alloyed with Mo or $\mathrm{Nb}$, for passenger cars and heavy trucks. These alloys show lower mechanical strength (classes 200 or $150 \mathrm{MPa}$ ), and the rotors are, for this reason, bigger and heavier. The high thermal conductivity is due to a greater amount of graphite in the microstructure, allowing lower temperatures in the region under friction, which contributes to an increase in life of the component [5].

Gray iron has good thermal conductivity due to the graphite phase, which is a excellent thermal conductor. Graphite flakes are interconnected and disposed in the form of plates, constituting an easy path for fast heat dissipation.

In ductile iron, spherical graphite particles are isolated from one another, the contribution of that phase for the thermal conductivity being very small.

Vermicular graphite, present in compact graphite iron (CGI), is also interconnected, resulting in intermediate mechanical and thermal properties between those of gray and ductile irons.

Mechanical and thermal properties of cast irons may be improved through the addition of alloying elements. In the case of CGI, the use of Mo and high levels of Si has been reported, for application in exhaust manifolds, with the purpose of improving thermal fatigue [6].

CGI is being used in Europe in railroad brake rotors where both thermal and mechanical stresses are intense. 
CGI is an alternative material that has not yet been thoroughly explored by the automotive industry, possibly due to the limited knowledge of its use in that type of application [7].

According to Zhang et al. [8], the wear resistance of compact graphite irons is greater than the wear resistance of gray and ductile irons, independent of contact pressure or sliding speed. This is due to an excellent combination between high mechanical resistance and good heat-transfer capacity, which gives the material good thermal fatigue peeling resistance [8].

Although the mechanical and thermal properties of the CGI are very well known, there is little information in literature relative to its use in brake rotors applications $[9,10]$. In this work, the wear performance of a CGI used in the manufacture of engine blocks is studied, aiming at its usage in brake rotors of large vehicles. The results are compared to the ones obtained in similar tests carried out with gray irons normally used.

\section{Experimental procedure}

Three types of gray irons were studied: one grade 250 (GI250), one high-carbon (GIHC), one alloyed with Ti (GI250Ti) and a compact graphite iron, whose chemical compositions and basic mechanical properties are shown in Table 1.

The microstructural characteristics of the four classes of irons are indicated in Table 2. It was noted that the microstructures of the gray irons were very similar to each

Table 1

Chemical composition (wt.\%) and mechanical properties of irons

\begin{tabular}{lcccc}
\hline & GI250 & GIHC & GI250Ti & CGI \\
\hline $\mathrm{C}$ & 3.54 & 3.73 & 3.49 & 3.63 \\
$\mathrm{Si}$ & 2.15 & 2.07 & 2.27 & 2.06 \\
$\mathrm{Mn}$ & 0.51 & 0.78 & 0.53 & 0.51 \\
$\mathrm{P}$ & 0.054 & 0.058 & 0.052 & 0.04 \\
$\mathrm{~S}$ & 0.1 & 0.085 & 0.09 & 0.015 \\
$\mathrm{Ti}$ & 0.012 & 0.014 & 0.028 & 0.014 \\
$\mathrm{Cu}$ & 0.69 & 0.56 & 0.71 & 0.47 \\
$\mathrm{Cr}$ & 0.034 & 0.27 & 0.060 & 0.035 \\
$\mathrm{Sn}$ & 0.061 & 0.039 & 0.064 & 0.045 \\
$\mathrm{Hardness}(\mathrm{HB})$ & $195 \pm 5$ & $180 \pm 5$ & $195 \pm 5$ & $220 \pm 5$ \\
UTS (MPa) & 255 & 240 & 255 & 460 \\
\hline
\end{tabular}

Table 2

Microstructural characteristics of irons

\begin{tabular}{lllll}
\hline & GI250 & GIHC & GI250Ti & CGI \\
\hline Graphite $(\%)$ & 12 & 12.5 & 10 & 12 \\
L/D & 5 & 4.7 & 6.5 & 2.8 \\
Type & IA3 & IA3 & IA3 & $90 \%$ IIIA5-10\% VIA6 \\
Pearlite (\%) & 99 & 99 & 99 & 85 \\
Ferrite $(\%)$ & $<1$ & $<1$ & $<1$ & 15 \\
\hline
\end{tabular}

other, consisting basically of pearlite and flake graphite, the only difference being their graphite content. The CGI, however, presented also ferrite in its microstructure, besides pearlite, vermicular graphite and traces of spherical graphite. The $L / D \sim 5$ ( $L$ : length and $D$ : width) average value of the graphite aspect ratio of the three gray irons shows that its morphologies are very similar, and clearly different from CGI which presents a $L / D$ close to 3 .

The wear tests were performed in a PLINT-TE67 pin-on-disc wear-testing machine, where the load is pneumatically applied. The pin specimens were manufactured from brake pads used in the Mercedes Benz Sprinter vans. They had a square base (area of $144 \mathrm{~mm}^{2}$ ) and were ground with sand paper grade 400 . The disc specimens were manufactured in iron with $70 \mathrm{~mm}$ in diameter and $7 \mathrm{~mm}$ in thick and surface finished by polishing with $1 \mu \mathrm{m}$ diamond paste.

Chemical analysis carried out on the pins (pads), revealed the predominant presence of iron, barium, aluminum and silicon and small proportions of sulfur, calcium, manganese and copper. According to Anderson [11], these brake pads should be classified, as metallic.

The wear tests have been carried out as follows: a cyclic pressure of $0.7,2$ and $4 \mathrm{MPa}$ was applied through the pin to the spinning rotor $(500 \mathrm{rpm})$. Pressure was applied for $1 \mathrm{~min}$ leaving the rotor spinning unloaded for the next $3 \mathrm{~min}$, the total cycle being $4 \mathrm{~min}$ long. During the cycles, a blower cooled the pin-rotor system. The test lasted $20 \mathrm{~h}$, with the completion of 300 cycles (loading-unloading). During the cycles, the temperatures reached by pins were determined by means of thermocouples inserted in the pins, as shown in Fig. 1. The normal and tangential forces were also recorded.

The wear in rotors and pins was measured by the accumulated mass loss after the cycles. At least three rotors of each material were tested in order to verify the reproducibility of the results.

\section{Results and discussion}

The accumulated wear of the disc specimens as function of pressure and type of iron are shown in Fig. 2. It can be seen that for any testing pressure, the wear of CGI discs is higher than the wear measured for all tested gray irons, except for the $4 \mathrm{MPa}$ conditions, in which GI250 presented the greatest wear. The three gray irons showed similar wear for the lower applied pressures ( 2 or $0.7 \mathrm{MPa})$, considering the standard deviations.

Fig. 2 shows that the wear of gray irons decreases as the applied pressure decreases. The same is not valid for CGI, where wear does not change monotonically with decreasing pressure.

One would expect that CGI, which presents the highest mechanical strength among the four studied materials, could be the most wear resistant material. The results, however, do not show such a relation. The large amount of ferrite 


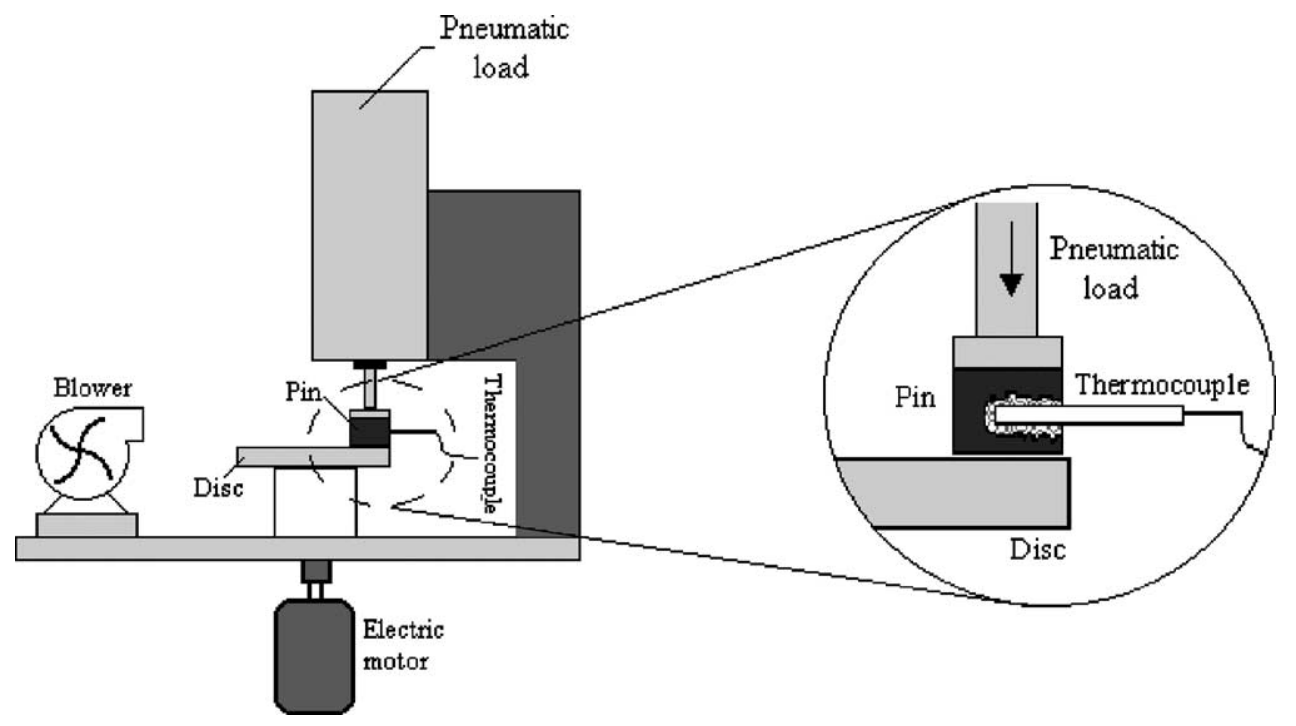

Fig. 1. Schematic representation of pin-on-disc wear-testing machine.

in the CGI metallic matrix, and the lower heat dissipation capacity of this material could be the main causes of this behavior.

Considering the wear average values, the GI250Ti presented greater wear resistance for all applied pressures, indicating that removal of material is reduced by some other microstructure characteristic and not only due to the lubricating action of graphite that protects the surface against wear [12].

Hard titanium carbide particles improve the wear resistance $[4,7]$. These particles, with diameters between 2 and $6 \mu \mathrm{m}$, are dispersed in the relatively soft metallic matrix. Ti levels lower than $0.015 \%$ precipitates less than 40 hard particles $/ \mathrm{mm}^{2}$, leading to high values of wear, while levels higher than $0.025 \%$, precipitates more than 60 hard particles $/ \mathrm{mm}^{2}$, promoting low wear. A value of $0.02 \%$ of $\mathrm{Ti}$ is used as reference in irons used in brake rotors and drums. The GI250Ti iron used in this study has $0.028 \% \mathrm{Ti}$ explaining the lower wear rate observed.

Fig. 3 shows the pin wear for the four different disc materials. In this case, considering the standard deviation of the results, one can state that the wear of the pins, is practically

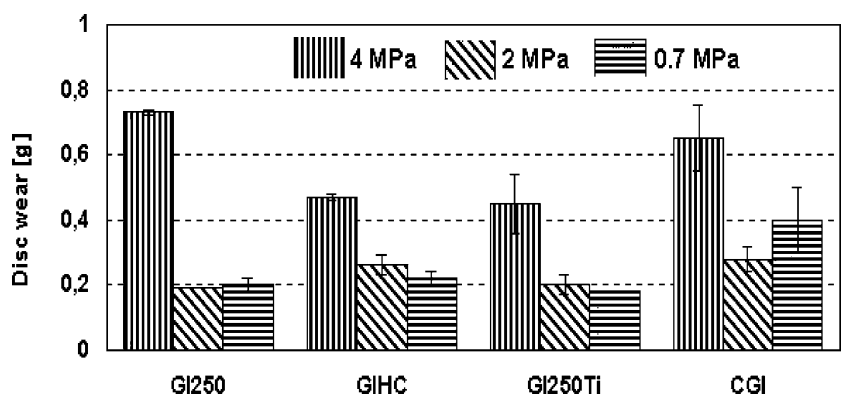

Fig. 2. Discs wear as function of testing pressure.

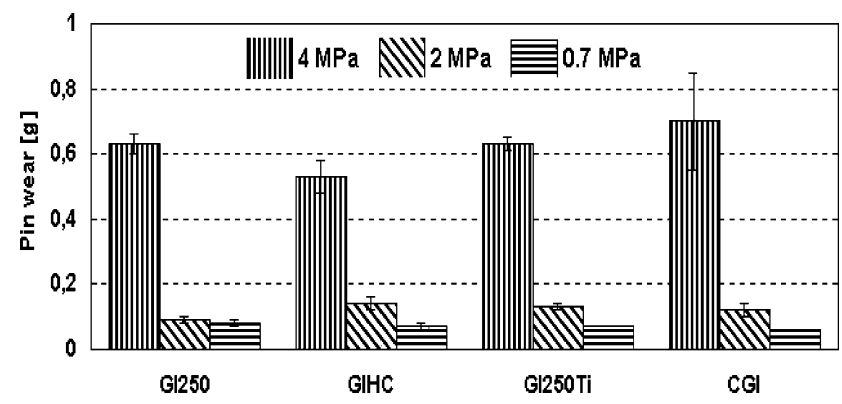

Fig. 3. Pins' wear as a function of testing pressure and different disc materials.

the same, independent of the tribologic pair and friction conditions recorded.

In Table 3, one can see that friction forces and temperatures are quite the same for the three gray irons. When testing CGI discs, the highest friction forces and temperatures were reached.

In Fig. 2, it was shown that CGI presented the worst wear resistance and, at a first glance, it would not be selectable for manufacturing brake rotors. It is worth noting, however, that the high friction forces developed during the tests suggest that a CGI rotor would show higher braking efficiency, and hence, it would require lower braking pressures, compared to those necessary to stop a vehicle-with the same momentum in the same braking distance-having gray iron rotors.

Therefore, CGI tests using lower applied pressures (3.3, 1.7 and $0.4 \mathrm{MPa}$ ) were carried out to reach the same order of friction forces obtained for the gray irons. Table 4 shows the results including an extra test carried out with $1.3 \mathrm{MPa}$ applied pressure to evaluate more precisely the tendency of the CGI results.

One can see that the friction forces and temperatures reached by CGI tested at pressures of $3.3,1.7$ and $0.4 \mathrm{MPa}$ 
Table 3

Friction force and temperature as function of pressure and type of iron

\begin{tabular}{|c|c|c|c|c|c|c|}
\hline & \multicolumn{2}{|l|}{$4 \mathrm{MPa}$} & \multicolumn{2}{|l|}{$2 \mathrm{MPa}$} & \multicolumn{2}{|l|}{$0.7 \mathrm{MPa}$} \\
\hline & Friction $(\mathrm{N})$ & Temperature $\left({ }^{\circ} \mathrm{C}\right)$ & Friction $(\mathrm{N})$ & Temperature $\left({ }^{\circ} \mathrm{C}\right)$ & Friction $(\mathrm{N})$ & Temperature $\left({ }^{\circ} \mathrm{C}\right)$ \\
\hline GI250 & $315 \pm 10$ & $200 \pm 10$ & $110 \pm 10$ & $90 \pm 5$ & $35 \pm 10$ & $60 \pm 5$ \\
\hline GIHC & $325 \pm 10$ & $210 \pm 10$ & $110 \pm 10$ & $85 \pm 5$ & $35 \pm 10$ & $55 \pm 5$ \\
\hline GI250Ti & $340 \pm 10$ & $210 \pm 10$ & $110 \pm 10$ & $95 \pm 5$ & $35 \pm 10$ & $60 \pm 5$ \\
\hline CGI & $360 \pm 10$ & $240 \pm 10$ & $165 \pm 10$ & $115 \pm 5$ & $55 \pm 5$ & $70 \pm 5$ \\
\hline
\end{tabular}

Table 4

Friction force and temperature as function of pressure in CGI

\begin{tabular}{|c|c|c|c|c|c|c|c|}
\hline & $4 \mathrm{MPa}$ & $3.3 \mathrm{MPa}$ & $2 \mathrm{MPa}$ & $1.7 \mathrm{MPa}$ & $1.3 \mathrm{MPa}$ & $0.7 \mathrm{MPa}$ & $0.4 \mathrm{MPa}$ \\
\hline Friction $(\mathrm{N})$ & $360 \pm 10$ & $320 \pm 20$ & $160 \pm 10$ & $105 \pm 10$ & $80 \pm 5$ & $55 \pm 5$ & $35 \pm 5$ \\
\hline Temperature $\left({ }^{\circ} \mathrm{C}\right)$ & $240 \pm 10$ & $195 \pm 10$ & $115 \pm 5$ & $90 \pm 5$ & $75 \pm 10$ & $70 \pm 5$ & $60 \pm 5$ \\
\hline
\end{tabular}

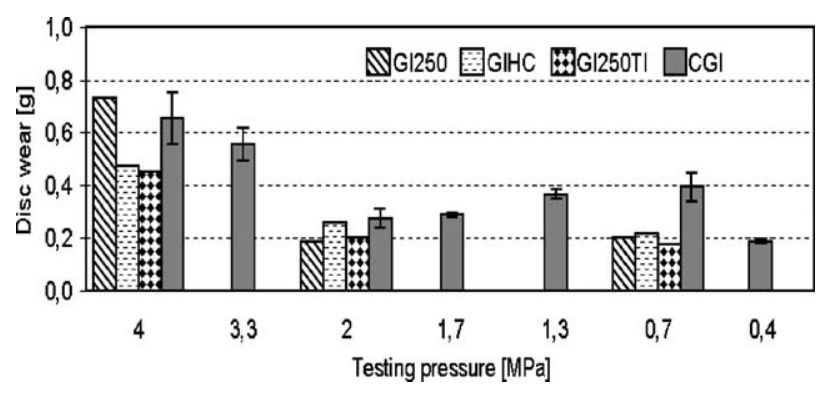

Fig. 4. Wear of the tested irons CGI as function of applied pressure.

are similar to those reached by gray irons tested at 4,2 and $0.7 \mathrm{MPa}$, respectively.

These results confirm the hypothesis of a greater braking efficiency of brake rotors made of CGI, for a given applied pressure.

The wear results obtained for CGI tested at lower applied pressures are shown in Fig. 4. The mass loss decreases when the pressure is decreased between 4 and $2 \mathrm{MPa}$, followed by an increase for pressures between 2 and $0.7 \mathrm{MPa}$ and finally the mass loss decreases again when the pressure is decreased to $0.4 \mathrm{MPa}$. The results show that the wear of CGI is greater (or at least the same) than that observed in the tested gray irons, even when the friction forces and contact temperatures are the same observed for gray irons.

\section{Conclusions}

The pin-on-disc wear tests carried out with CGI and three different gray irons allowed to conclude:

- For given applied pressures, the wear of compact graphite iron is higher than that of gray irons.

- For given applied pressures the pins' wear was practically the same, independent of the iron.
- During gray irons tests, at given applied stresses, practically the same friction forces and temperatures were observed, independent of the grade. Compact graphite iron, on the other hand, showed greater friction forces and temperatures than those observed in gray irons.

- During CGI tests using lower applied pressures $(3.3,1.7$ and $0.4 \mathrm{MPa}$ ), carried out to reach the same order of friction forces obtained for gray irons, it was observed that the wear is greater or at least the same of that observed for gray irons.

\section{Acknowledgements}

The authors acknowledge Indústria de Fundição Tupy for the donation of the cast irons, COBREQ for the donation of the brake pads and FAPESP (Process no. 99/11603-9) and CAPES for financial support.

\section{References}

[1] Y. Jimbo, et al., Development of high thermal conductivity cast iron for brake disk rotors, SAE Technical Paper Series, International Congress and Exposition, Detroit, MI, 1990.

[2] A. Esposito, J. Thrower, Machine Design, Delmar Publishers Inc., 1999.

[3] M. Macnaughta, Cast iron brake discs-a brief history of their development and metallurgy, Technical Report, Foundryman, 1998, $321 \mathrm{pp}$.

[4] B.J. Chapman, G. Mannion, Titanium-bearing cast iron for automotive braking applications, Foundry Trade J. 25 (1982) 232.

[5] W. Keiner, H. Werning, Hochgekohlter Grauguss GG-15HC-Idealer Werksotoff fuer Bremsscheiben und Bremstrommeln, Konstruiren Giessen 15 (4) (1990) 4.

[6] W.L. Guesser, L.C. Guedes, Desenvolvimentos recentes em ferros fundidos aplicados à indústria automobilística, in: Proceedings of the IX Simpósio de Engenharia Automotiva, AEA, São Paulo, 1997. 
[7] A.M. Pye, Applications of some of the news cast irons (technical report), Mater. Des. 3 (1992) 534.

[8] Y. Zhang, Y. Chen, B. Shen, Investigation of tribological properties of brake shoe materials phosphorous cast iron with different graphite morphologies, Wear 166 (1983) 179.

[9] W.L. Guesser, et al., Production experience with compacted graphite iron automotive components, in: Proceedings of the AFS Congress, Dallas, 2001.
[10] S. Dawson, T. Schroeder, Compacted graphite iron offers a viable design alternative, Eng. Casting Solutions (Spring) (2000) 42.

[11] Anderson, A., Friction and wear of automotive brakes. Metals Handbook: Friction, Lubrication and Wear Technology, vol. 18, 1992, pp. 569-577.

[12] J. Sugishita, S. Fujiyoshi, The effect of cast iron graphite on friction and wear performance. I. Graphite film formation on gray cast iron surfaces, Wear 66 (1981) 209. 